\title{
DUTOS DE AR AUTOMOTIVOS PRODUZIDOS POR MOLDAGEM A SOPRO 3D EM DUPONT TM HYTEL® HTR 8441 TPC MAXIMIZA O DESEMPENHO DO MOTOR COM TURBOCOMPRESSOR REDUZINDO EMISSÕES E O PESO DOS COMPONENTES
}

\author{
Augusto Marcelino Lopes Dorneles Filho' ${ }^{1}$, Danilo Hideo Sato ${ }^{2}$ \\ DuPont do Brasil $1^{1}$, DuPont do Brasil ${ }^{2}$, Brasil \\ E-mails: augusto.dornelles@dupont.com ${ }^{1}$,danilo.sato@dupont.com²
}

\begin{abstract}
RESUMO
Os dutos de ar automotivos produzidos por Moldagem a Sopro 3D em DuPont ${ }^{\mathrm{TM}}$ Hytrel $^{\circledR}$ HTR 8441 TPC [1] maximizam o desempenho do motor com turbo compressor reduzindo emissões, reduzindo o peso dos componentes, e tornando os veículos mais eficientes, seguindo os modernos padrões da indústria automotiva mundial. A DuPont ${ }^{\mathrm{TM}}$ Transportation \& Advanced Polymers, desenvolveu uma linha de produtos que tornou possível a fabricação no Brasil, de um duto de ar integrado para motores turbo, que conecta o motor ao intercooler aumentando a eficiência deste sistema. Moldado por sopro 3D com termoplástico elastomérico a base de poliéster DuPont ${ }^{\mathrm{TM}} \mathrm{Hytrel}^{\circledR}$ rígido e tenaz, o duto de ar cumpre sua tarefa de maneira particularmente eficiente, já que resiste aos vapores de óleo e combustíveis, temperaturas elevadas de até $180^{\circ} \mathrm{C}$ e vibrações constantes, mantendo a solidez do sistema sob estas condições. Juntos, a combinação de menor peso, produção e montagem mais eficiente e a integração de funções (eliminando vários componentes intermediários), proporcionam uma vantagem de custo significativa em relação às opções tradicionais fabricadas em metais ou borrachas.
\end{abstract}

\section{SUMMARY}

The automotive air ducts produced by 3D Blow Molding with DuPont ${ }^{\mathrm{TM}}$ Hytrel $^{\circledR}$ HTR 8441 TPC maximize turbocharged engine performance by reducing emissions, reducing component weight, and making vehicles more efficient, following the modern standards of the world automotive industry. DuPont ${ }^{\mathrm{TM}}$ Transportation \& Advanced Polymers has developed a product line that made it possible to manufacture an integrated air duct for turbocharged engines in Brazil, which connects the engine to the intercooler, increasing the efficiency of this system. 3D blow molded with polyester-based elastomeric thermoplastic, DuPont ${ }^{\mathrm{TM}}$ Hytrel® rigid and tough, the air duct fulfills its task in a particularly efficient manner, as it resists to oil and fuel vapors, high temperatures up to $180^{\circ} \mathrm{C}$ and constant vibrations, maintaining the system solidity. Together, the combination of lower weight, more efficient production and assembly, and function integration (eliminating multiple intermediate components) provide a significant cost advantage over traditional options made of metals or rubbers.

\section{INTRODUÇÃO}

$\mathrm{Na}$ Indústria Automotiva, a tendência para motores menores, mais eficientes em termos de combustível e com maior desempenho, deve muito ao desenvolvimento dos motores turbo. Aumentos na potência e no desempenho do motor resultam em motores que geram mais calor 
e envolvem gases e produtos químicos mais agressivos, geralmente sob alta pressão. Tipos específicos de materiais como por exemplo Hytrel ${ }^{\circledR}$, para uso em sistemas de gerenciamento de ar, tais como dutos de ar, mangueiras de turbo compressor e vedações, são capazes de suportar as altas tensões mecânicas, temperaturas extremas e ambientes químicos agressivos exigidos ao longo da vida útil um veículo. Além disso, eles podem reduzir o peso em $50 \%$ e reduzir os custos em $20 \%$ em comparação com as opções metálicas, ao mesmo tempo em que proporcionam excelente resistência ao calor e ao envelhecimento em contato com os fluído automotivos.

Os dutos de ar operam em ambientes quentes e sob tensão constante, que envolvem pressão, óleo do motor e vapores. Essas condições podem induzir no rápido envelhecimento térmico da maioria dos materiais plásticos, com exceção dos de maior desempenho em termos de engenharia. Usando um tipo especialmente modificado de Hytrel ${ }^{\circledR}$, foram desenvolvidos dutos de ar de dois componentes, a primeira solução do gênero. Reduzir a peça para apenas dois componentes resultou em menor peso e produção e montagem mais eficientes, proporcionando uma economia significativa.

Os compostos de poliéster elastomérico Hytrel ${ }^{\circledR}$ auxiliam sobremaneira, a reduzir o peso e o custo em dutos de ar quente, mantendo excelentes níveis de desempenho por muito mais tempo do que produtos opcionais, apesar da exposição ao óleo quente, ar quente e outros produtos químicos automotivos agressivos.

No que concerne aos motores com turbo compressor que trabalham com temperaturas por volta de $150^{\circ} \mathrm{C}$ e pressões a partir de 2,5 bar. O poliéster elastomérico Hytrel ${ }^{\circledR}$ oferece e perfis de temperatura ideais e propriedades resistentes a produtos químicos para aplicações em dutos de ar para estes tipos de motores. Ainda, apresentam maior resistência ao calor, melhor flexibilidade em baixas temperaturas, maior resistência à fadiga por flexão, melhor resistência a óleo, combustível e ácido médios, além de reduzir os custos totais de processamento, visto que dutos de ar produzidos em Hytrel ${ }^{\circledR}$ são mais baratos que as alternativas metálicas e ainda com a integração de funções e diminuindo o número de componentes intermediários, reduz o número de junções, mitigando substancialmente o potencial de vazamentos.

A redução do tamanho do motor, a redução de peso, a turbo compressão, a injeção direta e a recirculação dos gases de escape são todas respostas às necessidades e desafios que a indústria automotiva brasileira está se defrontando, para alcançar maior economia de combustível, maior eficiência do motor e menores emissões de CO2. Mas esses avanços têm um preço.

Os motores turbo-assistido, geram mais calor e envolvem gases, fluidos e misturas ácidas de gás/ar mais agressivas, geralmente sob alta pressão. Muitos materiais tradicionais de construção não podem mais funcionar nos ambientes mais quentes, confinados e sob pressão presentes nestes tipos de motores.

Os sistemas de gerenciamento de ar integram muitos componentes, incluindo o turbo compressor, ressonador, intercooler, coletor de admissão de ar, recirculação dos gases de escape e sistemas fechados de ventilação do cárter com tubos de ar, mangueiras, vedações, juntas, buchas e membranas para conectar e vedar esses componentes.

Esses componentes vitais exigem materiais excepcionais para suportar as altas tensões mecânicas, os extremos de calor e frio e ambientes químicos agressivos durante a vida útil do 
veículo. Eles também devem ser produzidos de forma sustentável e ajudar as montadoras a atender a legislação global de emissões evaporativas cada vez mais rigorosa - incluindo US PZEV Fase III, LEV II e Euro 5 e 6 - demonstrando baixa a zero permeabilidade a gases e fluidos de motores. Para o caso de Dutos de Ar para motores turbo-assistidos, a Dupont desenvolveu tipos de Hytrel ${ }^{\circledR}$, específicos para esta aplicação, que quando processados pela técnica de Sopro 3D, conseguem atender os requisitos e especificações da indústria automotiva para este tipo de aplicação. Desta maneira, que o formato integrado, mais leve, mais fácil de montar, mais seguro, diminuindo o número de operações, mitigou sensivelmente o custo total deste sistema.

A abordagem utilizada para este projeto de produção de dutos de ar integrado e de fácil montagem, foi bem-sucedida, porque implicou nos seguintes processos:

1- Levantamento das informações de potencial de mercado para este tipo de aplicação.

2- Identificação das principais necessidades técnicas no âmbito do ambiente de funcional de trabalho (presente no habitáculo do motor), manuseio das peças, montagem na linha, e controle/testes de garantia de funcionamento.

3- Seleção dos tipos de plásticos [2] de engenharia que poderiam atender ou superar estas necessidades técnicas, apoiados pelo uso de Softwares como o Mold-Flow e análise de elementos finitos.

4- Definição do processamento mais adequado para a produção deste tipo de componente de maneira robusta, constante, e altas produção e produtividade.

\section{O mercado potencial}

O tendência de se utilizar Dutos de Ar produzidos com a linha de produtos Hytrel ${ }^{\circledR}$, guarda estreita relação com a maior preocupação da indústria global e brasileira, no que concerne à diminuição do consumo de combustível, e na redução de emissões, seguindo a rota da agenda regulatória alcançada pelo segmento automotivo.

Na Figura 1, no gráfico da direita, é apontado o grau de emissões para diferentes países e regiões do mundo. No caso do Brasil, especificamente é mostrado um índice de emissões da ordem de $138 \mathrm{~g}$ de $\mathrm{CO} 2 / \mathrm{km}$ versus a Comunidade Europeia que exibe um índice de $95 \mathrm{~g}$ de $\mathrm{CO} 2 / \mathrm{km}$. O que implica, que a necessidade de melhorar esses índices no mercado Brasileiro é relevante. Assim como a moderna indústria automotiva persegue índices menores de emissões e se esforça para seguir regulamentações mais restritas, há também o desenvolvimento das novas tecnologias no que diz respeito aos veículos elétricos e autônomos, sustentabilidade ambiental e mudanças das preferências do consumidor, que impelem as indústrias para um caminho de alternativas de produtos, onde critérios de governança sustentável possam ser percebidos rapidamente pelos clientes: conforto, dirigibilidade, segurança, conectividade, compartilhamento, consumo menor e mais responsável, e finalmente a busca por um planeta mais limpo. No gráfico à esquerda, é mostrado que o crescimento nos países emergentes será de 2,6\% ao ano até 2024 (crescimento muito maior que os países desenvolvidos que variam de $-0,5 \%$ a $1,9 \%$ ). Ainda na parte superior do gráfico, é mostrado que o estimado em vendas de materiais para a área de transportes (segundo o IHS), é de U\$ 150 Bilhões e 65\% deste 
montante será direcionado para atender às regulamentações automotivas, investimento que crescerá ao redor de 1,5 $\mathrm{x}$ a taxa média do PIB Global (atingindo entre 4,5\% a 6,0\% ao ano).

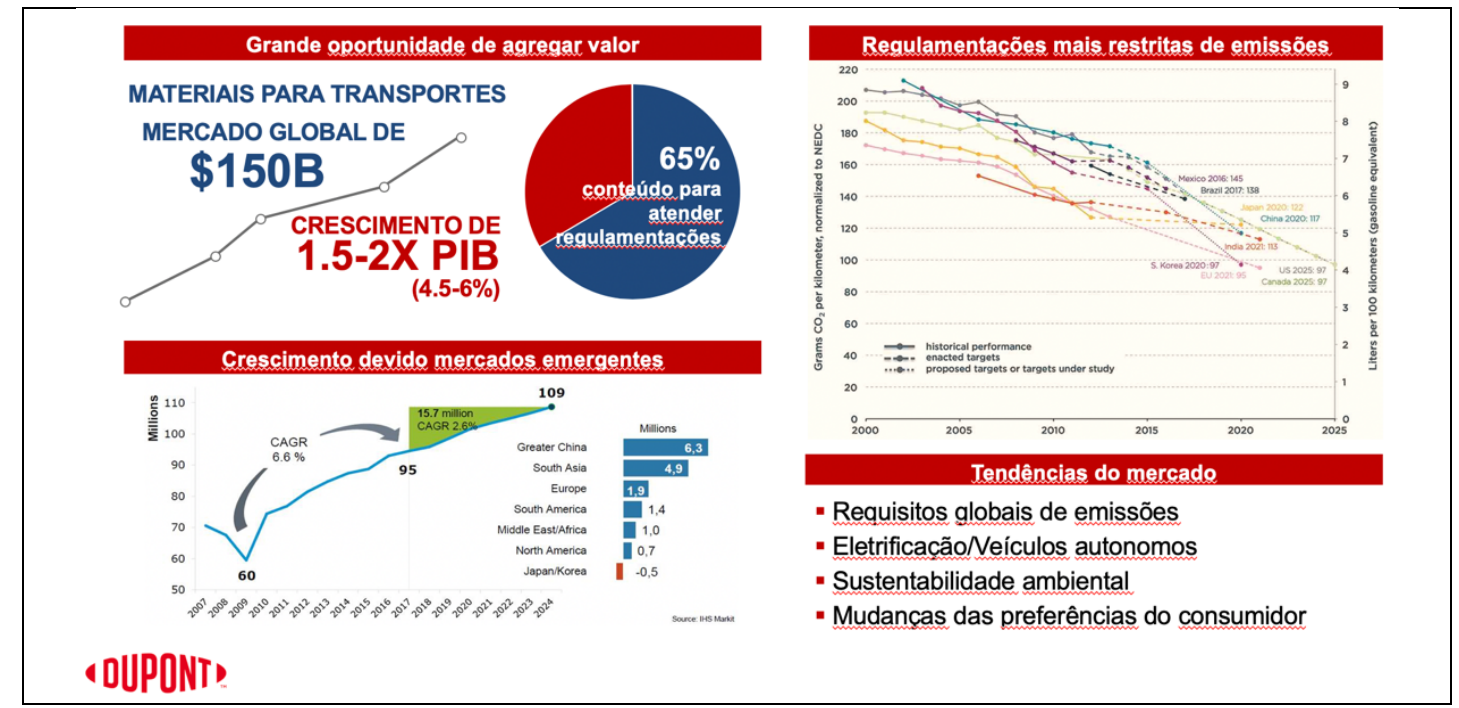

\section{Figura 1 : Transportes oportunidades no mercado global}

O aumento na participação de carros de motores menores (Figura 2) - até 1.6 litros (42\% em 2012, subindo para 62\% até 2020), substituindo motores maiores (acima de 1.7 litros), mantendo características de potência similares, mas com indicadores de desempenho similares aos motores maiores, mas com custos menores. E ainda as montadoras, tem diminuído o número de cilindros de seis para de quatro para 03 significantemente. Desta forma, os motores de 03 cilindros são menores, mais leves, tem menos componentes, mais baratos, consomem menos combustível, com menor índice de emissões, e com a percepção de potência de motores maiores. O conceito sustentável que se aplica neste momento é o 'Small is Beautiful'.

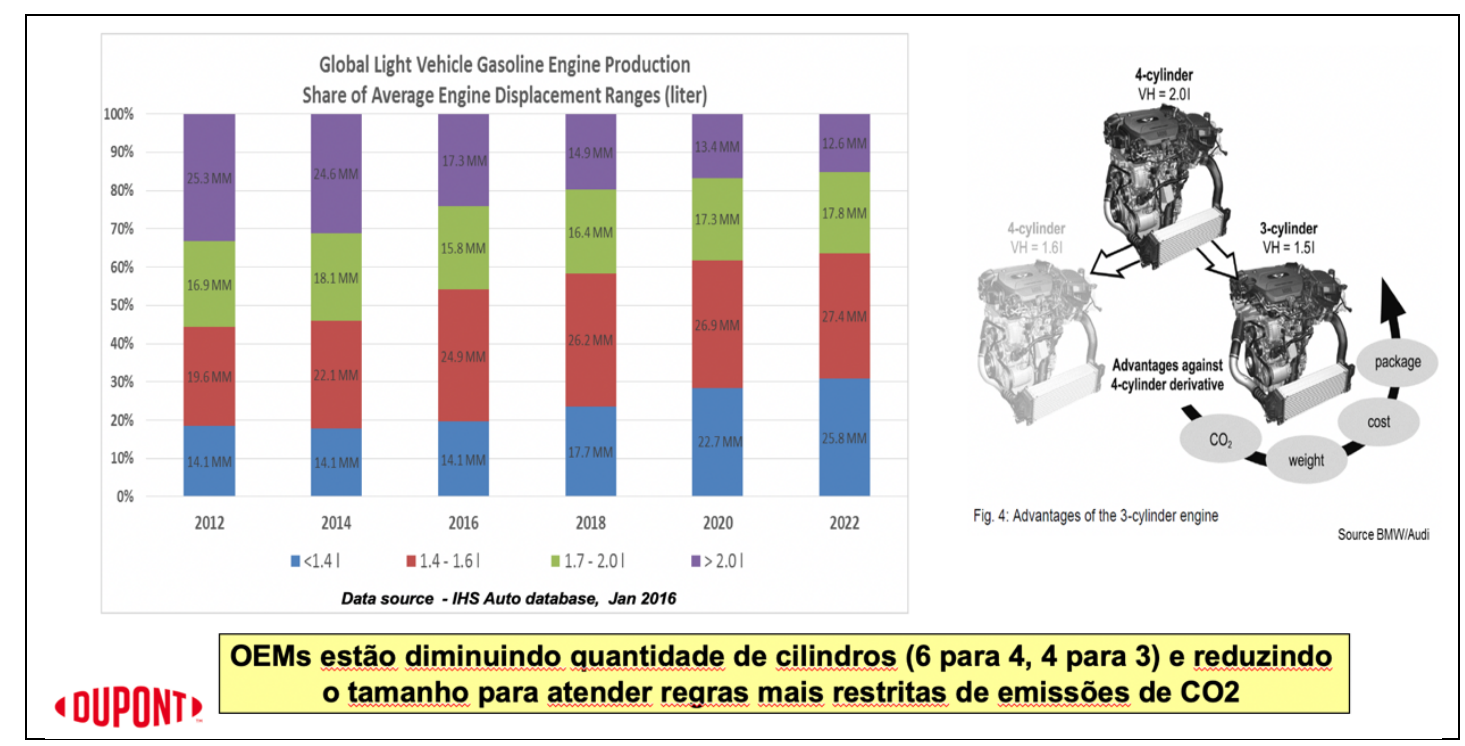

Figura 2 : Evolução de motores globalmente

Na Figura 3, percebe-se o aumento relevante na fabricação de motores turbo e diminuição na fabricação de motores aspirados. De tal maneira, que de a participação de motores turbo no mercado em 2014 era de $33 \%$ (ou 29,2 milhões) e para 2020 a participação chegará a $50 \%$ (ou 56,2 milhões de unidades). Desta forma, o fato é que os motores turbo estão se tornando 
majoritários no mercado global, e isto deve continuar por muitos anos, devido a presença de carros híbridos (com motores elétricos e de combustão) antes da chamada era da eletrificação total dos motores).

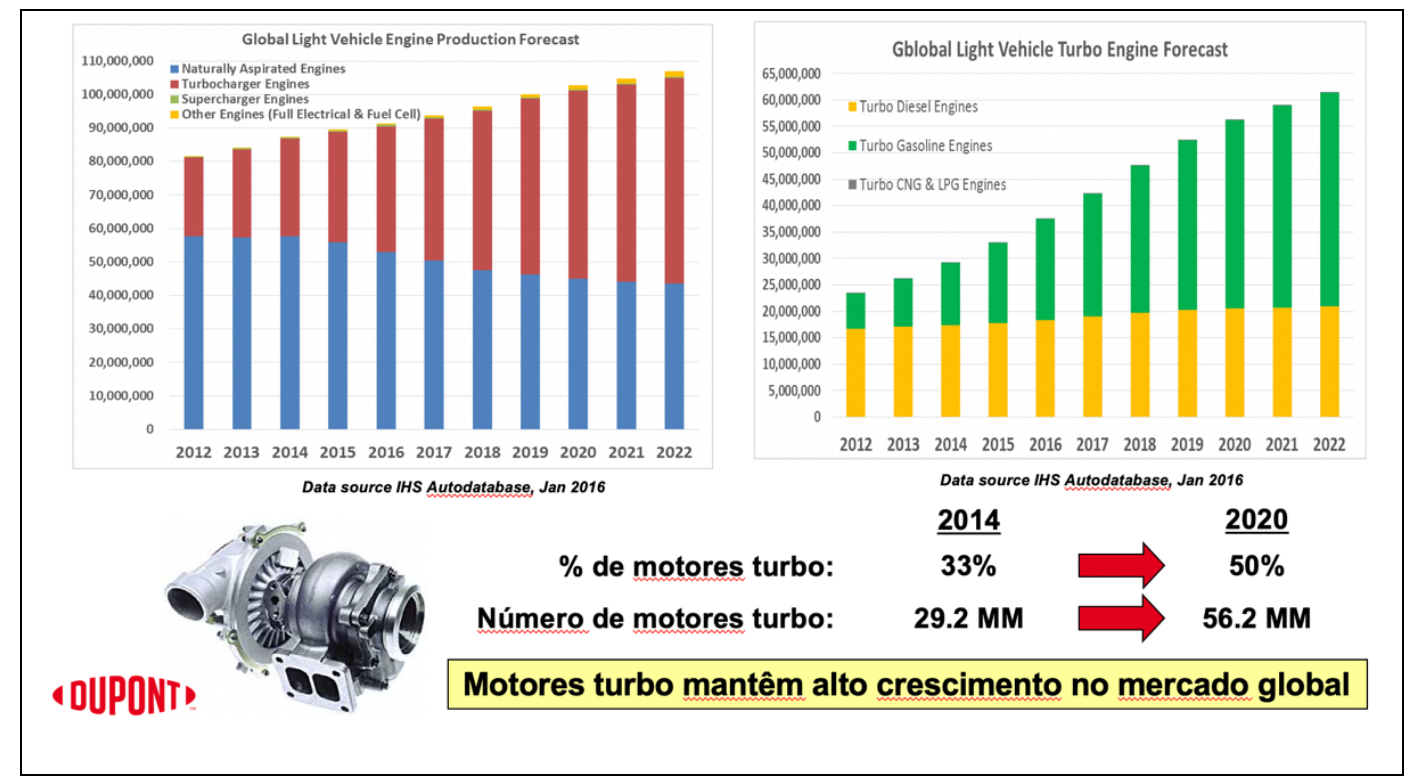

Figura 3: Previsão do mercado global de veículos leves turbo

\section{Identificação das principais necessidades técnicas}

Um tópico fundamental, foi entender as necessidades técnicas e as funções de desempenho no ambiente de trabalho deste sistema de dutos de ar acoplados ao sistema de gerenciamento de ar nos motores turbo.

Desta forma, na Figura 4, são apresentados os dutos acoplados à área do lado quente (duto na cor laranja) e à área do lado frio (duto na cor amarela - siga a seta). Fazendo a leitura da figura, pode-se entender o funcionamento básico do sistemas de dutos de ar. Assim, o ar contido no filtro, alimenta o turbo compressor, o turbo cumpre sua função de comprimir o ar limpo, o que faz a temperatura do ar elevar-se, o ar então aquecido passando pelo duto de ar transfere calor ao mesmo (área do lado quente - cor laranja), então é conduzido ao CAC (Charge-Air-Cooler), onde se esfria, passando pelo duto de ar (área do lado frio - cor amarela) e alimenta o coletor de admissão, que finalmente enviará este ar ao motor de combustão. 


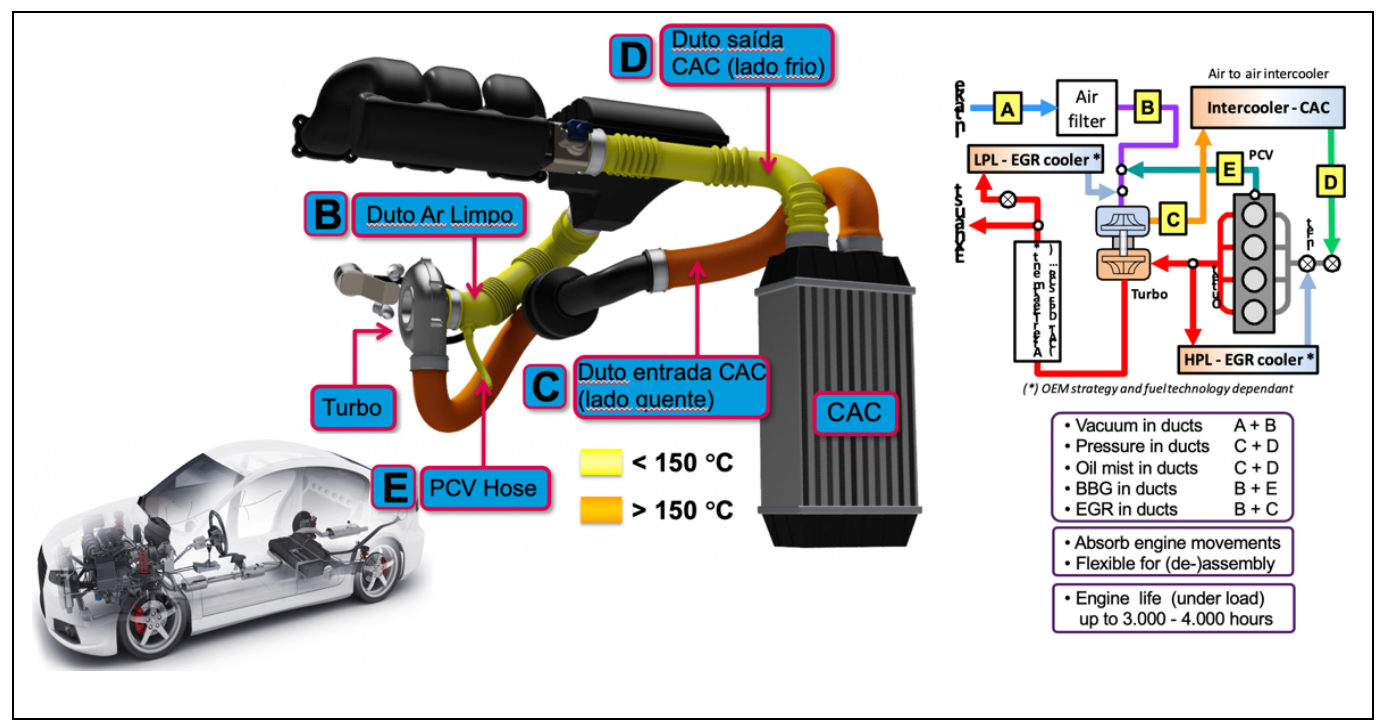

Figura 4: Aplicação de Dutos de Ar para Motores Turbo

\section{Seleção do material}

A despeito da desconfiança que cerca alguns dos componentes em plásticos que se destinam às aplicações automotivas, (e uma das principais razões para isso, são as elevadas temperaturas presentes em algumas áreas do automóvel), as grandes indústrias do setor não deixam de conceber novos projetos em polímeros de alta performance, para aplicações tidas como críticas em termos de resistência geral. Os plásticos de engenharia são escolhidos devido a seu fácil processamento, e sua flexibilidade em propiciar desenhos mais complexos, com boa estabilidade dimensional e uma excelente resistência à corrosão em ambientes de hostilidade química. Atualmente, o consumo de plásticos em alguns carros brasileiros já alcança quase $130 \mathrm{~kg}$ de plásticos nos seus interiores e/ou exteriores, o que ajuda a reduzir o peso total do automóvel, aumentando a economia de combustível, reduzindo os custos de processos, aliada a uma excelente aparência superficial. No caso dos dutos de ar, foi importante balizar os seguintes aspectos:

1- Flexibilidade de 'design' (geometria da peça): possibilidade de aliar-se convolutas a secções planas e lisas, formatos curvos e ao mesmo tempo rígidos e tenazes, permitindo a integração de funções e reduzindo o número de componentes intermediários.

2- Processabilidade: a escolha pela moldagem a sopro 3D, demonstrou-se produtiva, e adequada mesmo nos aspectos de estabilização das paredes do duto moldado.

3- Propriedades a curto e longo prazo [3], principalmente às ligadas aos parâmetros térmicos (resistir às temperaturas próximas a $150^{\circ}$ Celsius), mecânicos (Módulo de Flexão, Tenacidade), químicos (fluidos presentes na região do habitáculo do motor), estabilidade dimensional (prevenir vazamentos), dureza e aparência superficial (evitar perfurações), baixa densidade (diminuir peso), reciclabilidade (uso resíduos de préconsumo e de fácil reciclagem), soldabilidade, etc. 
Alguns aspectos que levaram à seleção do poliéster elastomérico para este dutos de ar (Figura 5) foram: faixa de temperaturas presentes na região do moto, entre $100^{\circ}$ Celsius e $210^{\circ}$ Celsius, as oportunidades de integração de componentes intermediários, e os principais benefícios/valores percebidos: redução do custo final do sistema em $20 \%$, redução do peso de $50 \%$, e redução de 6 componentes com implicação direta na segurança funcional e diminuição no número de operações de montagem.

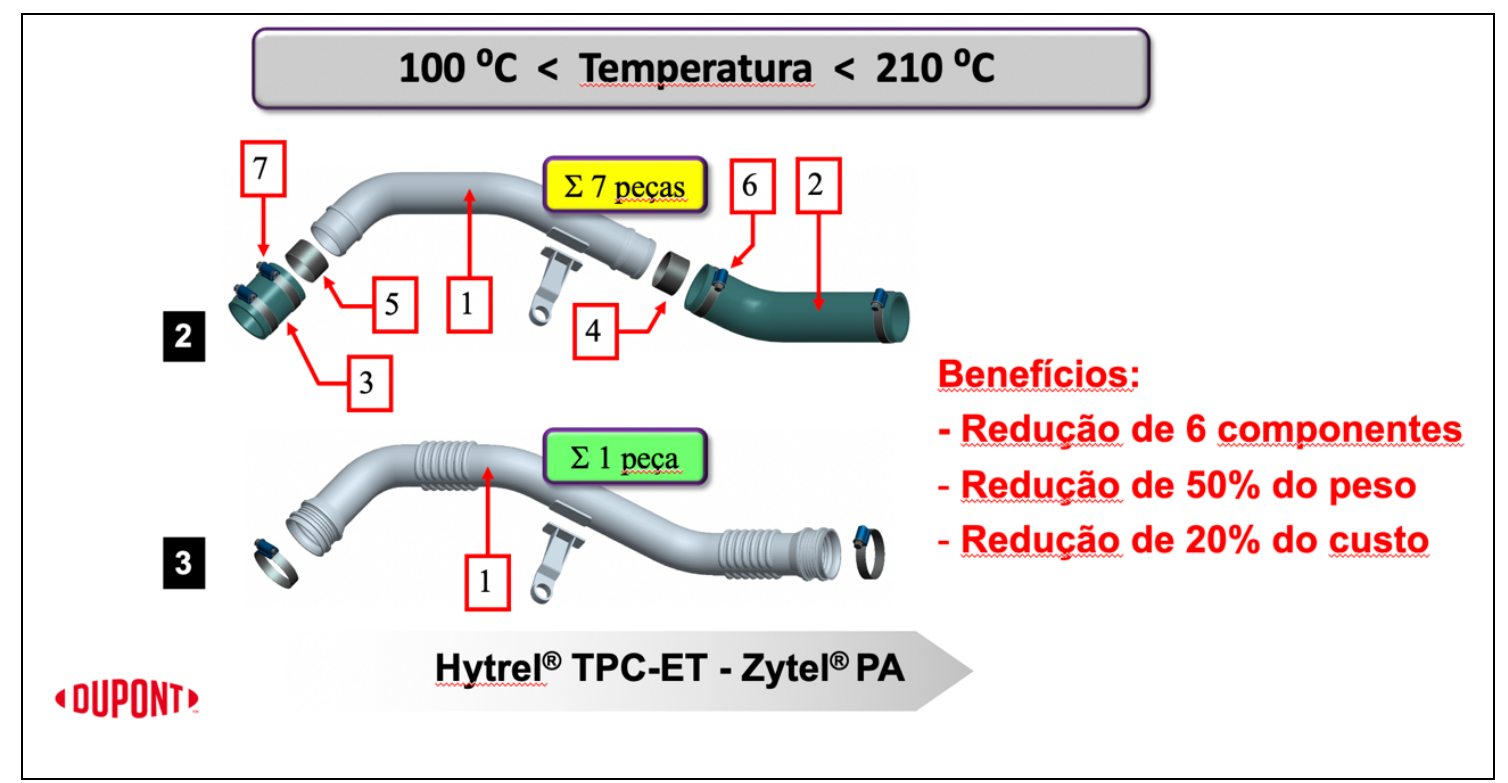

Figura 5: Dutos de ar para motores turbo - oportunidades de integração

\section{Definição de Processo}

A definição do processamento mais adequado, para um duto de ar, em geral se apoia nos processos convencionais, de extrusão, sopro e de injeção. Isto porque, são processos consolidados na indústria de plásticos, conhecidos pela robustez de resultados e por serem mais baratos. Entretanto, neste caso se procurou uma maneira diferente, porque o duto de ar final, precisaria apresentar: homogeneidade de paredes, linhas de emenda de alta resistência, ciclos baixos, baixa geração de rebarbas e robustez de moldagem (típica dos processos de injeção e extrusão), mas precisaria também se combinar com características típicas de moldados por sopro convencional (agora chamado de moldagem a sopro 2D), como componentes extensos, radiais, curvilíneos, e com formatos de peças ocas. Assim, aliando-se a sucção à tecnologia de moldagem por sopro, uma empresa na Itália (ST - Soffiaggio Tecnica) desenvolveu um processo que se convencionou chamar Moldagem por Sopro 3D, onde componentes como os dutos de ar podem ser produzidos com esta combinação de características finais.

A Figura 6 demonstra o processo de sopro 2D (muito utilizado para moldagem de embalagens (frascos principalmente), desta forma o molde aberto é alimentado com um 'parison' (tubo de material em estado visco-elástico que é alimentado por uma rosca de extrusão, e forçado através de um cabeçote (do tipo 'pescoço de cisne') e com paredes ajustadas por uma matriz que define os diâmetros internos e externos deste tubo (definindo a espessura média das paredes). O molde então é fechado sobre a superfície deste 'parison', uma agulha sopradora é inserida na parte inferior do tubo, que pela pressão do ar soprado, leva o material contra as 
paredes do molde fechado. Decorrido, o tempo de resfriamento do componente, o molde é aberto, as rebarbas são cortadas (ou usinadas) e o componente final é obtido. Este processo é muito utilizado na indústria de plásticos, mas não é suficientemente robusto para as necessidades de um duto de ar, que não pode exibir linhas de emenda ou permitir a geração excessiva de rebarbas (visto o custo de um plástico de engenharia). Ou seja, há uma limitação em sua utilização, no âmbito de 'design' (desenho do produto), gasto excessivo de material, e por consequência de produtividade.

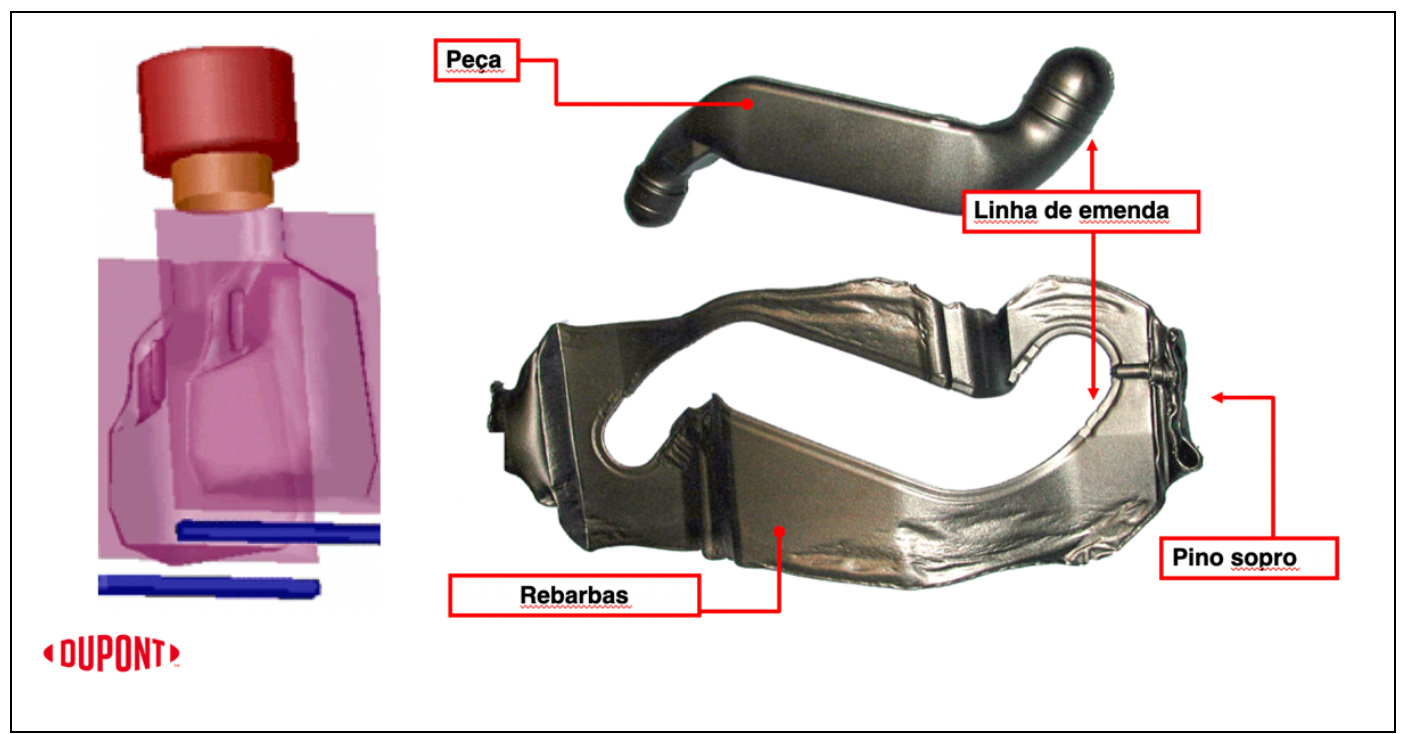

Figura 6: Moldagem por sopro convencional (2D)

A Moldagem a Sopro por 3D é exemplificada na Figura 7. Neste processo, a primeira diferença já é vista em relação ao molde, neste caso, o molde se encontrará fechado para o início do processo com o parison previamente extrudado para dentro dele. $\mathrm{E}$ através de um sistema de sucção, as paredes deste tubo são dispostas quase contra as cavidades do molde, e em seguida é disparada uma carga de sopro, que forçará as paredes do parison a tomarem a forma final das cavidades do molde. A definição das espessuras da parede do componente, é possível pela programação de um pino cônico descentralizado, que permite a correção das espessuras finais das paredes do produto. Este processo, propicia a produção de peças quase sem rebarbas e com geometrias complexas, gerando superfícies praticamente isentas de linhas de emenda.

O sucesso deste projeto, após a análise de mercado, foi devido a estudo aprofundado das necessidades técnicas funcionais relacionadas às propriedades intrínsecas presentes na linha de produtos $H_{y t r e l}{ }^{\circledR}$, à avaliação das condições presentes na região do motor e área de atuação dos dutos de ar (lado quente e/ou lado frio), às demais necessidades técnicas funcionais e, fundamentalmente, tendo como objetivo viabilizar a produção destas aplicações em um processo de Moldagem de Sopro 3D, que conferiu características de produto e produtividade únicas à produção de sistemas de dutos de ar. 


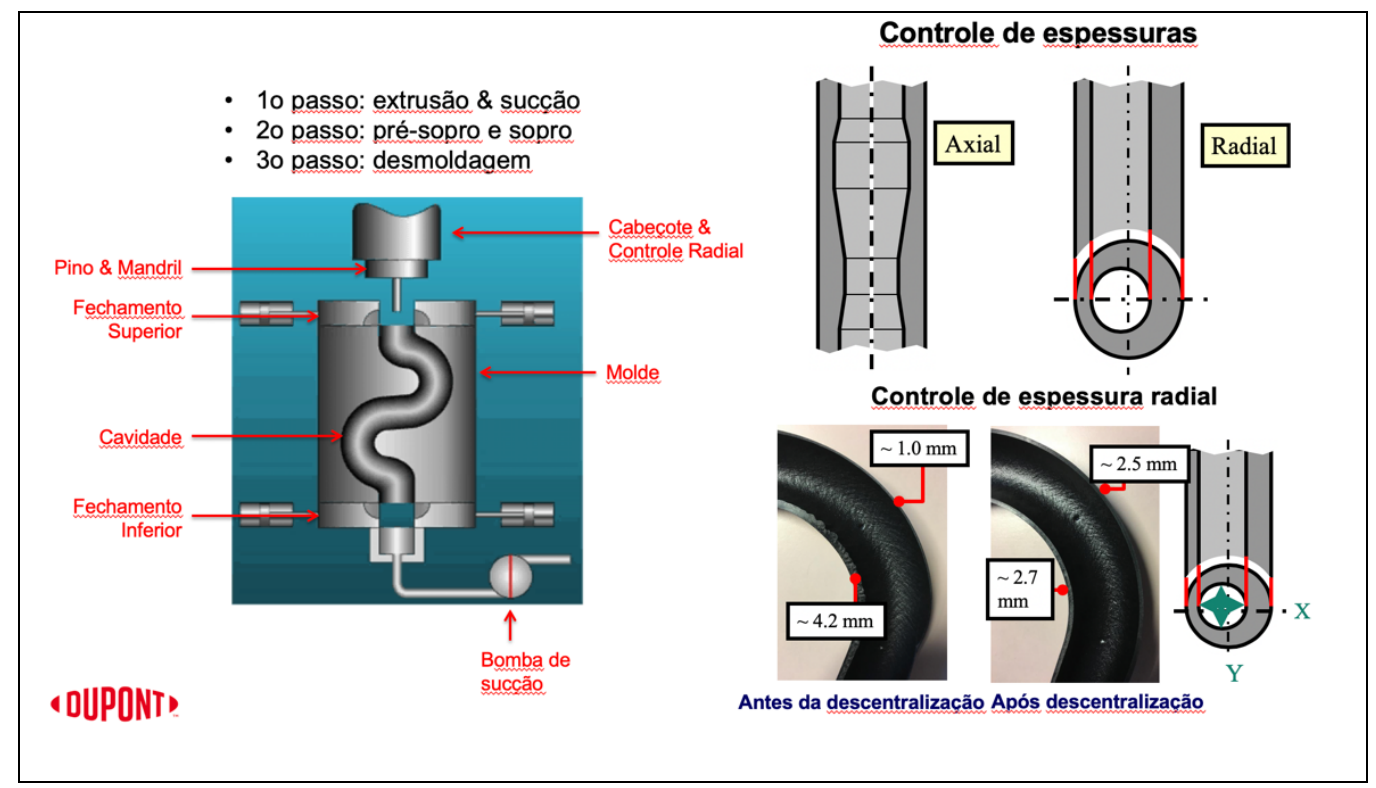

Figura 7: Moldagem por sopro sucção 3D

A Figura 8 demonstra as razões de sucesso deste projeto, após o estudo de mercado. Foi determinante contar com um profundo estudo das necessidades técnicas funcionais, uma avaliação das condições presentes na região do motor, área de atuação dos dutos de ar (lado quente e/ou lado frio), e demais demandas técnicas operacionais. Esta fase realizada, estabeleceu-se uma avaliação das propriedades intrínsecas presentes na linha de produtos Hytrel ${ }^{\circledR}$ e pelo suporte de sistemas de Software Mold-flow e Elementos Finitos utilizados na Dupont, dirigiu-se à produção destes dutos de ar, em um processo de Moldagem de Sopro 3D (também presentes nos laboratórios da Dupont), que conferiu características de produto e produtividade únicas a sistema de dutos de ar.

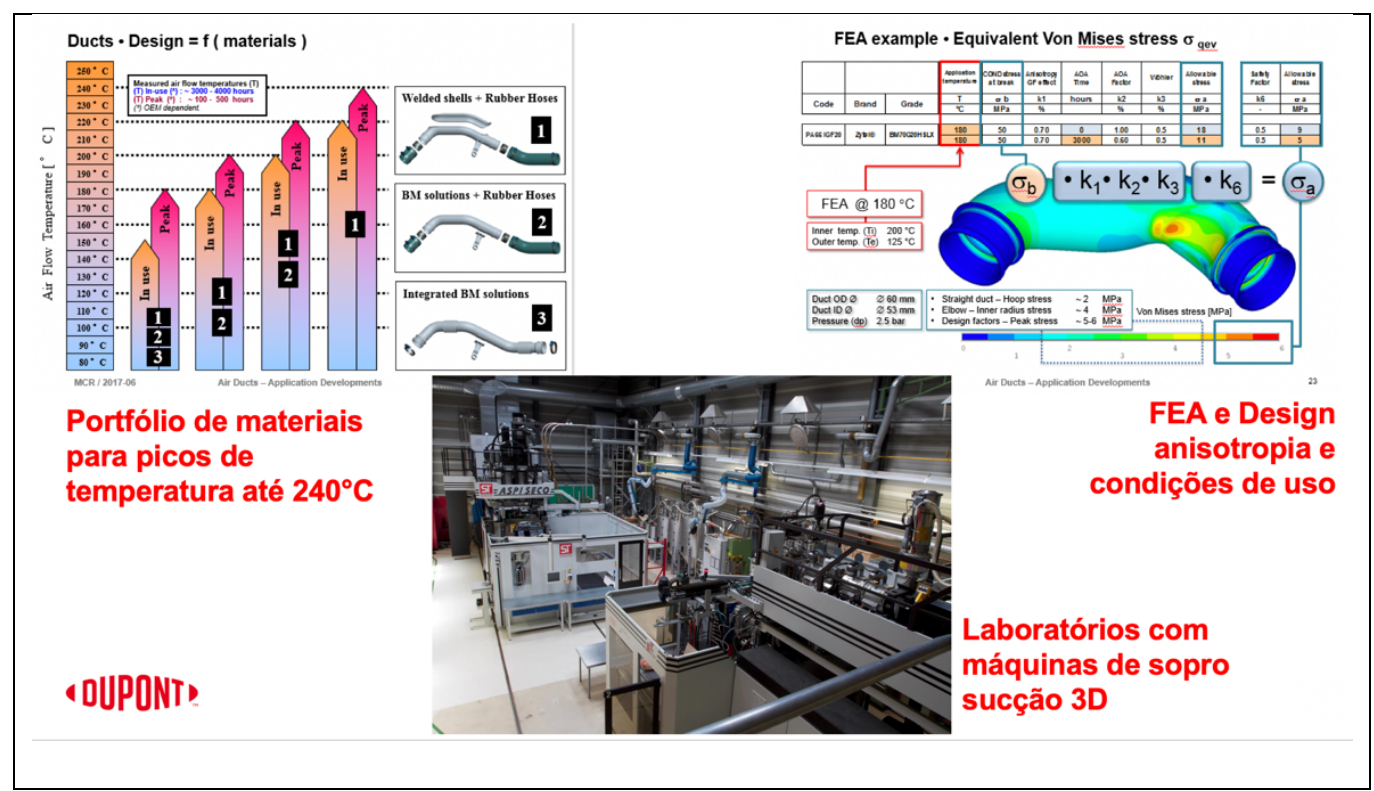

Figura 8: Desenvolvimento de moldagem sopro sucção 3D 


\section{CONCLUSÃO}

Para o caso de Dutos de Ar para motores turbo-assistidos, a Dupont desenvolveu tipos de Hytrel ${ }^{\circledR}$, específicos para esta aplicação, que quando processados pela técnica de Sopro 3D, conseguiram atender os requisitos e especificações da indústria automotiva para este tipo de aplicação. Assim, o formato integrado, mais leve, mais fácil de montar, mais seguro, diminuindo o número de operações, mitigou sensivelmente o custo total deste sistema. A abordagem utilizada para este projeto implicou:

1- Levantamento das informações de potencial de mercado para este tipo de aplicação.

2- Identificação das principais necessidades técnicas no âmbito do ambiente de funcional de trabalho (presente no habitáculo do motor), manuseio das peças, montagem na linha, e controle/testes de garantia de funcionamento.

3- Seleção dos tipos de plásticos de engenharia que poderiam atender ou superar estas necessidades técnicas, apoiados pelo uso de Softwares como o Mold-Flow e Análise de elementos finitos.

4- Definição do processamento mais adequado para a produção deste tipo de componente de maneira robusta, constante, e altas produção e produtividade.

Portanto, as tendências de mercado, apontam favoravelmente para o incremento de produção de motores turbo-assistidos por muitos anos. Neste cenário, a produção de sistemas de dutos de ar em plásticos de engenharia como o Hytrel ${ }^{\circledR}$, não apenas cumpre uma agenda econômica real, mas também cumpre uma agenda de sustentabilidade já que a sua utilização, diminui a geração emissões, melhora a eficiência do sistema. E ainda, corrobora, para a redução custo total desta alternativa, diminui o peso do componente, e melhora substancialmente a qualidade do sistema como um todo.

\section{REFERÊNCIAS}

[1] DUPONT. Automotive air ducts and turbocharger hoses. Increasing performance in automotive air ducts and turbocharger hoses. Disponível em:

https://www.dupont.com/products-and-services/plastics-polymers-resins/elastomers/uses-andapplications/automotive-air-ducts.html. Acesso em 22/maio/2019.

[2] ASHBY, M. F. Material Selection in Mechanical Design. Butterworth. Heinemann. Oxford, 2000. CRAWFORD, R.J. Plastics engineering. Pergamon Press. Oxford, 1987.

[3] DORNELLES FILHO, Augusto M. L.; ATOLINO, Walter - Plásticos de engenharia seleção eletrônica no caso automotivo. São Paulo: Artliber - 2009. 